\title{
Computer English Teaching Model Based on Multimedia Platform
}

\author{
http://dx.doi.org/10.3991/ijet.v11i08.6050 \\ Shaohua Shi \\ Inner Mongolia University of Finance and Economics, Huimin, Hohhot, Inner Mongolia, China
}

\begin{abstract}
Currently, multimedia-assisted foreign language teaching is a topic of high interest in the field of foreign language teaching. The combination between multimedia and foreign language teaching enables the teaching activity to integrate functions, such as words, phrases, sounds, images, figures and animations which can arouse and stimulate the students' enthusiasm and initiative as well as improve the teaching efficiency. However, the insufficient study of current foreign language teaching on both of the theories and practices of the multimedia-assisted foreign language teaching results in an unsatisfactory outcome of the multimedia-assisted teaching utilized by many foreign language teachers in middle school. Based on the knowledge and analysis of the status quo of the multimedia-assisted foreign language teaching and its design, this paper systematically discusses its contents of listening, speaking, reading and writing as well as its design, aiming at promoting teachers to spontaneously use the multimedia in the foreign language teaching, taking the maximum advantage of the multimediaassisted teaching.
\end{abstract}

Index Terms-computer English teaching; multimedia platform; teaching method; system development

\section{INTRODUCTION}

Multimedia-assisted foreign language teaching is regarded as the latest developing trend which revolutionizes the traditional means and methods of foreign language teaching. Containing many new teaching ideas, it brings foreign language teaching into a more modern and reasonable era [1]. The new method has attracted numerous teachers and students to make use of it, and relevant theoretical discussions and teaching practices continue to emerge. Nevertheless, in the absence of a complete set of a theoretical system in guiding and evaluating the courseware and the teaching practices of the multimediaassisted foreign language teaching, many participants feel aimless and less confident and even frustrated. As a new and special way of teaching, it firstly should conform to the principles of foreign language teaching, including the principles of communication, cognition, culture and emotions.

\section{AdVANTAGES OF MUlTIMEDIA-ASSISTED FOREIGN LANGUAGE TEACHING AT THE MidDLE SCHOOL LEVEL}

Strong advocation of the multimedia-assisted foreign language teaching is because of the key features and advantages of multimedia technologies. Its key features consists of diversification, interaction and integration of the information carrier while its advantages are presented as follows:

\section{A. Audio-visual Combination Conforms to Students' Perception}

Research in cognitive psychology reveals that $83 \%$ of learning is visual, and $11 \%$ is auditory; namely, the information obtained both visually and aurally accounts for $94 \%$ of total learning, which explains the important role of both visual and auditory senses in learning activities [2]. Multimedia-assisted foreign language teaching can use the audio-visual combination to express learning contents and provide the students with direct and vivid perceptual knowledge, which enables it to mobilize the students' visual and auditory senses and largely enhance their degree of understanding and memory. For example, when explaining the word "candy" through multimedia, its pronunciation and specific image will show up with a click of the mouse. The students can grasp corresponding pronunciation and spelling in a short time after they get a perceptive understanding of its appearance. And thanks to the combination of plentiful vivid images and sounds, it mobilizes the students' visual and auditory senses. Additionally, it conforms to their perception rule and helps them grasp the knowledge in a relaxed and fun atmosphere.

\section{B. Creating a Real and Natural Language Scene and Triggering Learning Interests}

Language is not just a system of symbols for communication but a kind of communicative behavior resulting from specific scenes. Real and natural learning scenes serve as the premise and foundation for the students' obtaining knowledge, which can inspire and maintain their learning interests, and also make this kind of interest last throughout the whole process of the teaching activities. By utilizing multimedia technology, the teacher presents the students vivid images and combines forms such as music and cartoon to stimulate their senses, and offers them a realistic and familiar language context. In this way, the teacher activates the students' learning interests and inspires their motivation and enthusiasm for communication. For instance, in teaching the article of Charlie Chaplin (SEFCIB), multimedia technology can be used to show some clips of Chaplin's humorous shorts. In the cheers and laughter, the students can get a direct perception of Chaplin's style of performance, while also obtaining some words or phrases such as stick, moustache, comedy, silent, swing and so on. In addition, the teacher can give the students a chance to conduct dubbing for the silent film to cultivate their ability of freely using the language in a certain context. In short, the application of multimedia technology presents the students a real language context and creates a language acquisition environment free from the restraint of the mother tongue as well as making them feel motivated to actively participate. 


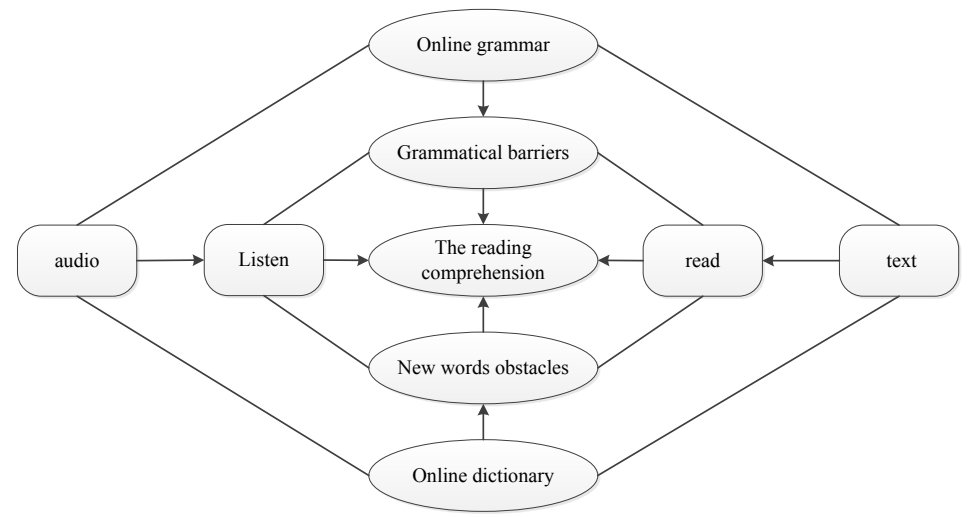

Figure 1. The process of reading while listening

\section{Offering a Communication Opportunity with Meaning as the Core}

As for foreign language learning, not all the language input can be understood or absorbed by the learners. So the learners also must pay attention to the unknown language elements and negotiate their meaning through communicating with others as well as actively construct their own language system [3]. However, most of the oral exercises and communications in the traditional foreign language class are comprised of sentence types and conversations in the textbook. The students often learn by imitation or recitation, but many of them are unable to use those sentences in real life situations and lack of the capability of carrying out meaningful communicative activities. Multimedia technology can offer them chances to use the target language during the process of discussing and completing certain tasks with other learners, the teacher or native speakers. For example, means such as e-mail and online chatting can offer the learner the opportunity of arranging and preparing communicative activities on one certain subject according to their own time and schedule.

\section{Suitable for Individualized Teaching}

The multimedia computer can arrange the learning process based on the different features of the students and conduct teaching according to the characteristics and routines of their way of thinking. Additionally, it can provide the students with conditions without time limits and they can learn in a way tha is suitable for each student and further enhance their learning efficiency. In the foreign language teaching, polarization begins to show up in the second grade of middle school, and individualized teaching could be a way to prevent this trend.

\section{E. Expanding Class Capacity and Improving Teaching Efficiency}

In the traditional teaching method, the teacher will explain the language points and write examples of usage on the blackboard which takes much time and is dull as well. However, multimedia-assisted teaching can vividly and directly deliver large amounts of information in a scientific and accurate way to enrich the teaching contents and expand the class capacity. The multimedia courseware can be pre-designed so that the teacher can save time spent on writing and made the class more compact and wellorganized, as well as make the difficult points clear at a glance [5]. As for the contents that are rather hard to understand, the teacher can give more examples to illustrate while preparing the courseware. While explaining, the teacher only needs to click the mouse, then the contents will be presented on the screen which greatly improves the efficiency of students' understanding and memory and provides the teacher with enough time to carry out exercises on reading, listening and speaking abilities.

\section{MultimediA-ASSISTED Foreign LANGUAGE LEARNING}

\section{A. Listening and Speaking Teaching}

\section{(1)Reading While Listening}

The integration of visual and auditory senses will have a better effect on the teaching of listening and speaking skills. When conducting listening and speaking teaching with multimedia assistance, the teacher can present the text and reading comprehension questions and at the same time play the supporting audio so that the students can do listening and speaking at the same time. This method helps to lower the difficulty of listening exercises and improve the students' ability to think quickly as well as improve the level of read comprehension. The online dictionary (Power Word) and online grammar of the multimedia computer can help the students to resolve learning problems at any time, both inside and outside the classroom. If a student does not understand, he/she can stop and think for a while or listen to it again, or ask for the help of the computer to exclude new words or grammar and then repeat listening [8]. Traditionally, the students become anxious and may easily miss or forget portions of the information while facing new words so that the feedback lags behind or even is paused. But the function of the multimedia platform is helpful to relieve their anxiety and strengthen their confidence. The process of reading while listening is shown in Figure 1.

\section{(2)Repeating While Listening}

Conventionally, students read a book which may weaken their ability of identifying language flow, missing language aspects such as long and short vowels, phonemes, consonants and consonant clusters, weak form, assimilation, liaison, repetition and rhythm in the language flow as well as the intonation and stress types. The students will repeat after the recording, but this does not allow them to better speculate the speaker's intention by observing the speaker' facial expressions and body gestures. They can only hear the voices. With the help of multimedia, some special English program can be made with pictures and the text can scroll with the audio synchronously so that the 
students can speak the language following foreigners in real scenes. They will repeat once after each part and then immediately follow the speaker's speed to listen to the next part, and so on. The students are able to accurately repeat according to the speed of listening and gradually increase the length of the repeated part as well as ues standard pronunciation, intonation and emotion. Figure 2 shows the process.

\section{(3)Oral English}

The multimedia computer is equipped with the function of visible interphone and voice chat that enable the teacher and students to see and hear each other even if they are in different locations. By multimedia-assisted teaching, the students can randomly and directly enter such learning center and communicate with foreign English teachers, as well as friends and lovers of English learning. Both of their listening skills and oral English have been practiced which largely improves their listening and speaking abilities.

\section{B. Teaching Reading}

Reading is a psychological process where the reader uses knowledge of the language, social and cultural background and the equipped learning strategy to understand the author's mind and emotion through perception and processing of the words and symbols in written form. Due to the interaction and mutual influences of various elements contained in the author's personal factors and the reading itself, people have different understandings of the same reading material. Reading comprehension is generally separated into three levels: surface understanding of the surface text, deep meaning using inferential understanding and judgment, and creative understanding [11]. It can generally be divided into three representative models: $\square$ the bottom to top model is the process of linear processing and understanding from parts to the whole which starts from identifying letters and finally reaches the goal of understanding of the whole article through the learning of words and sentences. $\square$ the top to bottom model considers reading as a process where the reader takes advantage of the knowledge already obtained and makes a prediction about the contents about to be read according to parts of the reading materials and finally verifies whether their prediction is right. Reading is never passively accepted, but is a process that requires the reader to actively and innovatively think and also seems like a kind of "Guessing and Predicting Game of Psychological language". $\square$ the interaction model emphasizes the mutual effect between the reader and the readings; Namely, focusing on the interaction between the knowledge of language such as words and sentences, and the background related to the topic grasped by the reader and the ideas and emotion delivered by the readings.

Multimedia-assisted teaching of reading refers to the idea that teaching basic knowledge and skills based on information technology reading and cultivating the students' ability to obtain the necessary information uses information technology with the help of the English reading teaching activities constructed by the information technology with the computer as its core. Additionally, it inspires the students to learn the rich connotation of the computer culture and expands their reading view.

\section{Teaching Writing}

Writing is a process of the interactions among the author, the work and the reader. As for the work, it refers to two fundamental elements: content and the language used to express it. The goal of teaching English reading is cultivating primary writing ability, including the forms of outline, abstract, short essay and simple practical writing. The arrangement of teaching contents can begin from how to use words and sentence structures and requires the students to continue the writing and further transits to fully grasping the writing skills of paragraphs, layout and short essays according to the essays presented or imitating examples of writing or certain scenes. If conditions permit, it should further train the students to grasp various writing types and their structures, such as descriptive writing, narrative writing, expository writing and argumentative writing.

Multimedia-assisted writing means the whole writing process of using the selected materials, input, code and words constructed by the computer system and network resources to process, polish, correct, check and compose as well as exchange writings. It also refers to the teaching of fundamental knowledge and skills of paperless writing by using the computer system and network resources. Multimedia-assisted foreign language writing is an integration of the author, editiing and the readers, and it is featured with interactive, synchronous and asynchronous teaching activities, flexible time and various and integrated results.

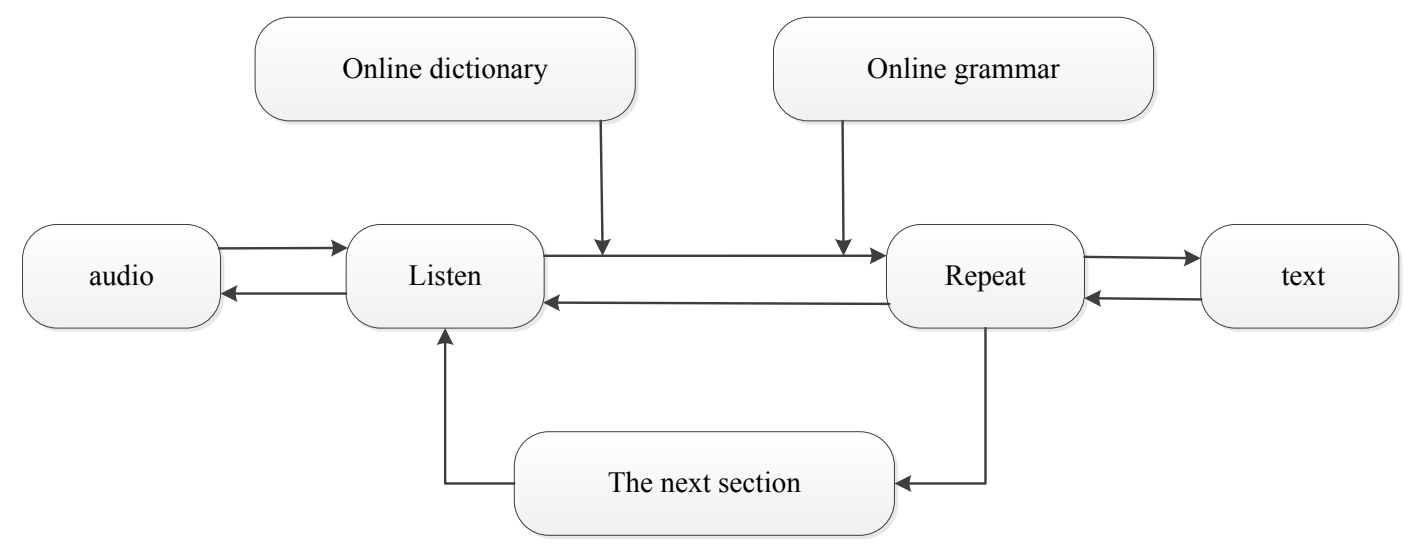

Figure 2. The standard pronunciation, intonation and emotion 
PAPER

Module 1

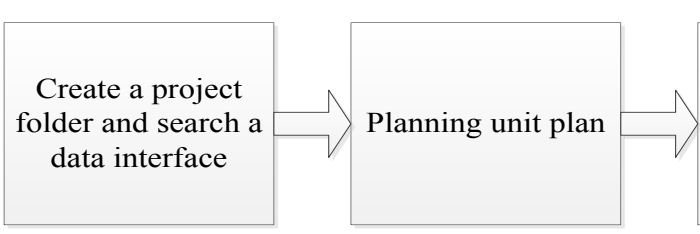

Module 3

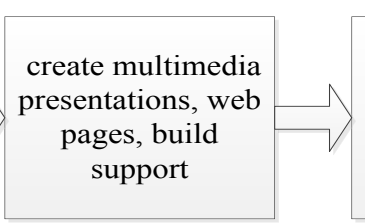

Module 4

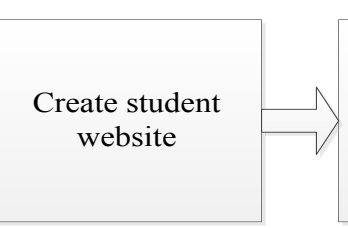

Module 5 gauge

Figure 3. Five modules for multimedia-assisted foreign language teaching in middle school

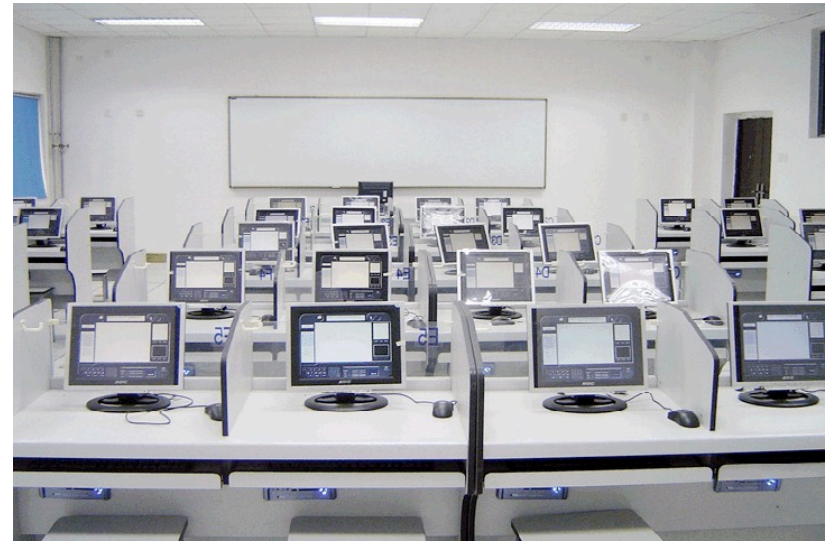

Figure 4. Multimedia-assisted foreign language teaching in middle school

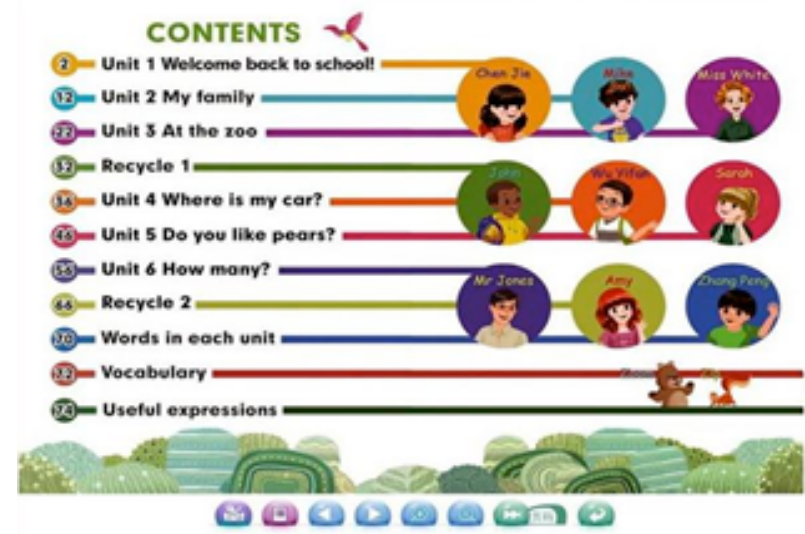

Figure 5. Multimedia teaching system

\section{Design OF Multimedia-ASSisted Foreign} LANGUAGE TEACHING IN MIDDLE SCHOOL

The design of this multimedia-assisted foreign language teaching in middle school is carried out in five modules, as shown in Figure 3.

\section{A. 4.1 "Start" Module}

This includes two activities in which the one is creating a project file to store all files, and the other is to search data for unit work. The project file is used to help the teacher manage various files created in the whole design process and any resources collected, and also provides the teacher convenience to access any file while teaching. The latter refers to when the teacher has to find some materials and resources needed by creating multimedia courseware on the internet or in the textbook and a variety of other references while designing the courseware. The design cannot function without them.

\section{B. "Scheduling Unit Plan" Module}

"Scheduling Unit Plan" plays the most important role in designing multimedia courseware, including assuring teaching targets, analyzing students, formulating teaching strategy, designing teaching activities and making assessments. All the following activities originate from this module, which serves as their design basis.

\section{C. "Creating Teacher-supported Material” Module}

The "Creating Teacher-supported Material" module consists of creating multimedia presentations and webpage and constructing support. The first is used in class and most teachers consider it as the entirety of multimedia teaching. However, in this model, it is only a presentation to be designed. It makes a brief introduction of the article and proposes requirements and tasks as well as provides the students with references for further learning, etc. Additionally, the so-called constructing support is to offer a supporting structure for the students and help them become independent learners.

As for the foreign language learning, not all of the language input can be understood or absorbed by the learners. So, the learners also need to pay attention to the unknown language elements and negotiate their meaning through communicating with others as well as actively construct their own language system. However, most of the oral exercises and communications in the traditional foreign language class are based on the sentence types and conversations in the textbook. The students often learn them by imitation or recitation, but many of them are unable to use those sentences in a real life setting and lack the capability of carrying out meaningful communicative activities. The multimedia technology can offer them the chances to use the target language during the process of discussing and completing certain tasks with other learners, the teacher or native speakers. For example, this means that e-mail and online chatting can offer the learner the opportunity of arranging and preparing communicative activities on one certain subject according to their own time and schedule, as shown in Figures 5-7.

\section{D. “Creating Students' Website” Module}

In the module of "Creating Students' Website", the teacher assumes that he/she is one of the students and creates a website as a student to offer the others an example. The teacher should make sure that the usage of language on the website is suitable for the students' ages and the design and contents comply with the expectations towards the students. Another consideration is whether the students can reach the learning goal. As a feature of this module, it places the students at the core and gives the classroom back to them. 


\section{E. “Formulating Evaluation Standards" Module}

In the "Formulating Evaluation Standards" module, the teaching evaluation goes through all the teaching and design process which includes the assessment of the teaching behavior of the teachers, and that of the students' completion of tasks. It is beneficial for both the teachers and students to consider their behavior and improve the teaching and learning effect.

\section{CONCLUSIONS}

Multimedia-assisted foreign language teaching is regarded as the latest developing trend which is revolutionary for the traditional means and methods of foreign language teaching. Containing many new teaching ideas, it brings foreign language teaching into a more modern and reasonable era. The new idea has attracted numerous teachers and students to make use of it, and relevant theoretical discussions and teaching practices continue to emerge. Nevertheless, in the absence of a complete set of a theoretical system in guiding and evaluating the courseware and the teaching practices of multimediaassisted foreign language teaching, many participants feel aimless and less confident and even frustrated. As a new and special way of teaching, it firstly should conform to the general principles of foreign language teaching, including the principles of communication, cognition, culture and emotions.

When using a network to carry out multimedia-assisted teaching, the teacher should work more as a guide and facilitator and adhere to the principles of "support" and "free". They cannot allow the students freely surf the internet, but should search and download appropriate webpages and article for English learning and narrow the internet access beforehand according to the students' level and class requirements. Moreover, they can establish a relevant learning website based on the teaching tasks and goals which enables the students to surf in the "small internet world" in order to reach the teaching goals. Meanwhile the teacher should attend to the cultivation of the students' abilities of for online study. As for the students, the important conditions for effective online learning is to grasp how to search and screen information. They have to master certain searching strategies, especially the skills of using searching engines. In addition, the teacher should help the students learn how to use the function of saving "favorites" and build web address lists for personal resources. Normally, the students can collect the websites that they think are useful for English learning into the favorites list and build one or several folders according to certain standards. When needed, they can directly search their favorites list and it may only take a few seconds, so it appears to be convenient and rapid. But the students must learn how to choose the information that is suitable for the current learning requirements and that can solve problems. Furthermore, they have to differentiate the true from the false information and make proper choices.

Altogether, multimedia-assisted foreign language teaching is not the sum of foreign language teaching and computer information, but an application of a new teaching model in foreign language teaching. The multimedia computer teaching system should be used in a reasonable and timely way and create the context for learning foreign language through which the students can perceive the materials through both their eyes and ears, thus improving

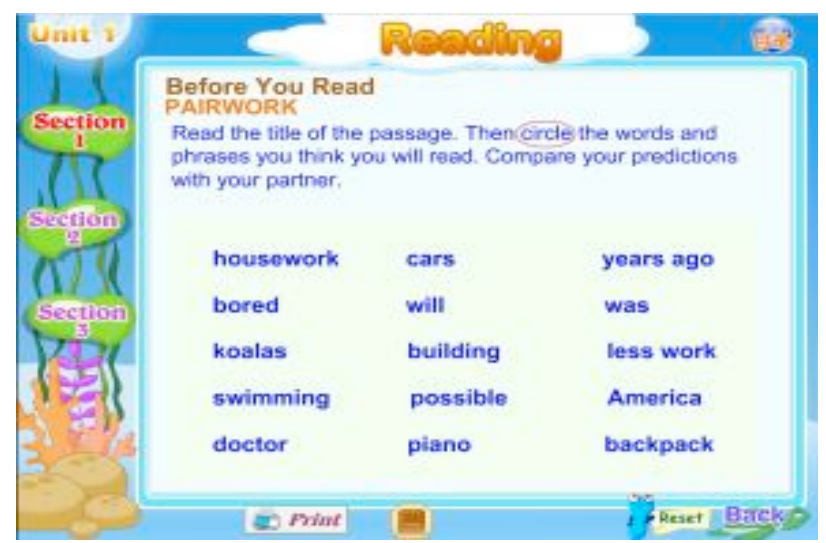

Figure 6. Multimedia teaching for reading

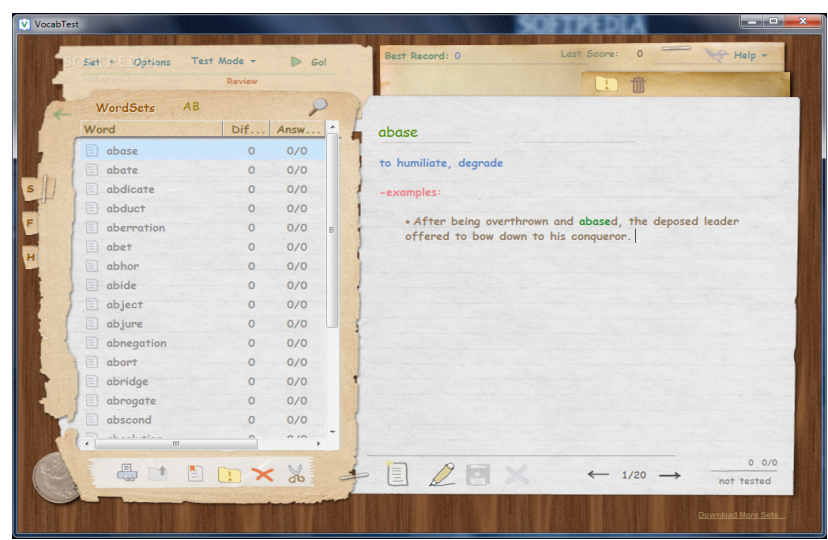

Figure 7. Multimedia teaching for writing

their language abilities. At the same time, full advantage should be taken of the guidance of the teacher, while allowing the students express their subjective opinions and creativity. Additionally, it is necessary to guide the students to do a large number of high quality comprehensive lessons including listening, speaking, reading and writing, which can make the students gain the fundamental knowledge of English, and exercise their basic skills of language and cultivate their abilities of thinking and expressing directly in English, as well as build a firm foundation for realizing actual communication in English. In this way, the true goal of introducing modern teaching methods using a multimedia computer to offer assistance to the foreign language teaching can be reached.

\section{REFERENCES}

[1] W. Sujua, "Research on college English autonomous learning mode based on computer networks," Lecture Notes in Electrical Engineering, Vol. 227, pp. 739-744, May 2013. http://dx.doi.org/10.1007/978-3-642-35398-7 93

[2] Y.Q. Hua, "Research of college English teaching based on computer network technology," Lecture Notes in Electrical Engineering, Vol. 206, pp. 375-382, April 2013. http://dx.doi.org/10.1007/978-1-4471-4790-9 48

[3] Z.Q. Li , "Higher vocational college "Computer network technology" course life scene design," Applied Mechanics and Materials, Vol. 65, pp. 1848-1851, March 2014.

[4] J. Song, "The English teaching model of cooperative learning in the network environment in higher vocational education". Communications in Computer and Information Science, Vol.218, pp.100-104, 2011. http://dx.doi.org/10.1007/978-3-642-23357919

[5] M. Rahkila, M. Karjalainen, "Evaluation of learning in computer based education using log systems". Proceedings-Frontiers in Ed- 
PAPER

\section{COMPuter English TEACHING MOdel BAsed On Multimedia Platform}

ucation Conference, vol. 1, pp.12-16, 1999. http://dx.doi.org/10.1109/fie.1999.839266

[6] H. Yamamoto, A. Ohtani, T. Kado, "Development and evaluation of computer-mediated education systems for customer engineers". IFIP Transactions A: Computer Science and Technology, vol.35, pp.205-214, 1993.

[7] Q.L. Sun, "Information under the network environment using computer information security technology". Proceedings-2015 International Conference on Intelligent Transportation, ICITBS 2015, pp.474-477. http://dx.doi.org/10.1109/icitbs.2015.122

[8] Z. Jun, "Study of task-based English language teaching using computer network," Proceedings-2012 IEEE Symposium on Robotics and Applications, ISRA 2012, pp. 600-603.

[9] Z. Jing, "Research on adaptive english learning model based on computer network," RISTI-Revista Iberica de Sistemas e Tecnologias de Informacao, Vol. 16, pp. 236-246, August 2015.

[10] M.Q. Xu, "The research on out-of-class autonomous English learning in computer-and network-assisted environment". Advances in Intelligent and Soft Computing, Vol. 36, pp. 453-459, 2011. http://dx.doi.org/10.1007/978-3-642-24775-0 71

[11] M. Young, "The Technical Writer's Handbook. Mill Valley," CA: University Science, vol. 22, pp. 98-109, May 1989.

[12] X.H. Chen, "The research on English autonomous learning monitoring theory and application in the network environment". $\mathrm{Ap}$ plied Mechanics and Materials, Vol.12, pp.6079-6082, 2014. http://dx.doi.org/10.4028/www.scientific.net/AMM.644-650.6079

[13] D.L. Yang, Zheng, H., "Research on the framework of new college English teaching mode integrating cooperative and autonomous learning in the network multimedia environment". ICETC 2010-2010 2nd International Conference on Education Technology and Computer, Vol.3, pp. 3256-3259, 2010.

[14] S.F. Han, S. Miao, "On college English teaching of writing in the network environment". 2011 International Conference on Multimedia Technology, ICMT 2011, pp.588-590. http://dx.doi.org/10.1109/ICMT.2011.6002176

[15] S. Li, "Survey research on college students' English learning anxiety in the computer network environment". ICCSE 2011-6th International Conference on Computer Science and Education, Vol.36, pp.1010-1012, 2011.

[16] Z. Lei, X. Wei, "The analysis of English network computer aid test system model and technology selection". 2011 International Conference on Internet Technology and Applications, vol.35, pp.236-248, 2011. http://dx.doi.org/10.1109/itap.2011.6006325

[17] X.M. Wang, Y.J. Yang, and X. Wen, "Research and design of computer-aided English textbook evaluation system". Proceedings of the 1st International Workshop on Education Technology and
Computer Science, vol.3, pp.913-917,

2009. http://dx.doi.org/10.1109/etcs.2009.741

[18] Z. Lei, X. Wei, "The analysis of English network computer aid test system model and technology selection". 2011 International Conference on Internet Technology and Applications, vol.35, pp.236-248, 2011. http://dx.doi.org/10.1109/itap.2011.6006325

[19] X.M. Wang, Y.J. Yang, and X. Wen, "Research and design of computer-aided English textbook evaluation system". Proceedings of the 1st International Workshop on Education Technology and Computer Science, vol.3, pp.913-917, 2009. http://dx.doi.org/10.1109/etcs.2009.741

[20] M. Rahkila, M. Karjalainen, "Evaluation of learning in computer based education using log systems". Proceedings-Frontiers in Education Conference, vol. 1, pp.12-16, 1999. http://dx.doi.org/10.1109/fie.1999.839266

[21] H. Yamamoto, A. Ohtani, T. Kado, "Development and evaluation of computer-mediated education systems for customer engineers". IFIP Transactions A: Computer Science and Technology, vol.35, pp.205-214, 1993.

[22] Y.J. Lan, Y.T. Sung, "Us read together: Development and evaluation of a computer-assisted reciprocal early English reading system”. Computers and Education, vol.53, pp.1188-1198, 2009. http://dx.doi.org/10.1016/j.compedu.2009.06.002

[23] Y. Zhike, "A new BP neural network algorithm and its application in English education evaluation". Telkomnika (Telecommunication Computing Electronics and Control), vol.11, pp.6441-6446, 2013. http://dx.doi.org/10.11591/telkomnika.v11i11.2970

[24] Y. Bai, "Comprehensive evaluation of education mode of university English model and swat analysis". Computer Modelling and New Technologies, vol.18, pp.1085-1088, 2014.

[25] J. Jia, W.C. Chen, "The further development of CSIEC project driven by application and evaluation in English education". British Journal of Educational Technology, vol.40, pp.901-918, 2009. http://dx.doi.org/10.1111/j.1467-8535.2008.00881.x

[26] J. Song, "The English teaching model of cooperative learning in the network environment in higher vocational education". Communications in Computer and Information Science, vol.218, pp.100-104, 2011. http://dx.doi.org/10.1007/978-3-642-23357919

\section{AUTHOR}

Shaohua Shi is with Inner Mongolia University of Finance and Economics, Huimin, Hohhot, Inner Mongolia, China (shish_imufe@hotmail.com).

Submitted 16 July 2016. Published as resubmitted by the author 22 August 2016. 